1934 Act, at Paulsgrove, on the slopes of Portsdown Hill overlooking Portsmouth. The rig is of a modern rotary type, 135 feet high, with a loading capacity of 400 tons, and stated to be capable of drilling to a depth of nearly three miles.

In his opening speech at the ceremony of setting in motion these works, Sir John Cadman referred to the enterprise, which all hoped would be eventually of great national importance, as "first and foremost a business venture, based on scientific observation, and organized with all the elaboration of detail that engineering skill and experience can suggest". He referred to the exploration company "as adventurers into the unknown, where, in the language of the oilfield, 'only the drill can tell" ".

From the strictly geological point of view, we may anticipate the drill telling of the bold structure of the Portsdown anticline which forms the conspicuous chalk background to the historic city. It may tell, also, of a sequence of rocks of which British geologists familiar with southern England stratigraphy could make a fairly shrewd guess both as to character and disposition. It may do much to strengthen conceptions of the subWealden structure. It will focus attention on Upper Jurassic possibilities, in particular the sorely tried and much over-rated Kimmeridge Clay. It will perhaps offer some explanation of the not far-distant natural gas and petrol smell of associated strata at Heathfield. It may even, in three miles of deep drilling, pierce totally unexpected and much older rock structures, including Carboniferous.

All this is reasonable. But let us not build too optimistically on the results in terms of oil. Rather let us hope for the unexpected and applaud the efforts now being made and the patriotism behind them. Should failure be the reward, which every British geologist, whatever may be his convictions, would doubly deplore in the interests both of science and the State, then may it be that science, in particular geology, may benefit lastingly by the knowledge thus made available, and possibly, as in the case of the sub-Wealden boring, industry benefit by discovery of a new mineral deposit, other than petroleum, of economic worth.

\title{
Pre-nuptial Medical Examination
}

$\mathrm{T}$ HOUGH vitamins and minerals are fashion. able ingredients of well-informed and polite conversation, by most people reproduction is not mentioned : it is disturbing, even repulsive. Yet men and women do mate and reproduce, and the State which is beginning to regard the child as a liability will sooner or later be forced to exhibit a very lively interest both in the number and the quality of the children that are born to be fed, housed, educated and employed or not employed.

Pre-nuptial certificates are even now demanded in certain countries, though usually by them eugenic considerations are completely disregarded. In Turkey, for example, marriage is forbidden to persons affected with active venereal diseases, mental disease or leprosy; whilst the marriage of persons afflicted with advanced and transmissible tuberculosis is delayed for as long as a year. In Norway there is a somewhat similar law prohibiting the marriage of a syphilitic, but in the case of other venereal diseases, epilepsy and leprosy, the other party to the marriage must be informed, and both parties warned by a physician of the possible consequences of marriage. On the schedule used in connexion with these cases there are questions relating to consanguinity, and information concerning the prohibition of marriages of close relatives. In Germany certificates of health before marriage are demanded of those persons applying for marriage loans; and for these, fairly comprehensive details of the family and personal medical history are required.

In Great Britain, it may be remembered, Lord Kilmaine, in the House of Lords on November 14 of last year, moved a resolution favouring the compulsory exchange of health certificates before marriage. It was suggested that there should be four kinds of such certificates: $(a)$ when both parties are perfectly fit to marry and to raise a family, (b) when the marriage should be delayed for 3-6 months, $(c)$ which permitted marriage without parentage, and $(d)$ which prohibited marriage altogether. Lord Kilmaine appeared to think that an actual medical examination in these cases was unnecessary, and that it would be enough if the two people concerned merely answered the questions of the physician concerning their general health and family history. As was to be expected, 
the proposals met with well-merited and strenuous opposition, for, quite obviously, the responsibility that was to be placed upon the medical practitioner would have proved quite intolerable.

However, when such a proposal is aired in Parliament, it is safe to assume that it has been, in one form or another, under discussion by a considerable portion of the population for a decade or more. There is no doubt that the demand for information and advice concerning those physical and psychological abnormalities that militate against the success of marriage, and the wish to prevent the birth of hereditarily diseased or defective children, has been growing apace, and already a great deal is being done by private individuals and organisations to give such advice and to guide this wish by means of bureaux and clinics. Further, it is now the common view that the family doctor treats not only the illnesses of the present generation but also prescribes for the children yet to be conceived. But it is the case that not all family doctors are possessed of the knowledge and wisdom which constitute the only warranty for the giving of advice of this particular nature.

So the Eugenics Society is to be congratulated for having prepared a scheme of voluntary prenuptial health examinations which is meant to help the family doctor. It was decided that at the present time no good purpose could be served by advocating any scheme of compulsory examination for the reason that this simply would not work, since anyone who resented being thus examined could easily conceal or distort important facts; whereas if the examination were sought voluntarily and entered into in good faith by both parties, there would be no such concealment, and at the same time a great deal of help could be given and a great deal of very important information relating to human and social biology amassed. It is assumed that most conscientious and seriousminded people embarking on marriage want to feel assured that they are sound in mind and body, and that such of these who know that in their family histories there are defects and derangements which they have reason to think are hereditary, also want to make sure that the children that they propose to have shall not repeat such hereditary blunders.

The scheme is a purely voluntary one, and it is placed at the service of those who wish to take advantage of it. The parties concerned present themselves before their own doctor, who applies to the Eugenics Society for the appropriate schedule. This consists of three parts. The first two of these, which are concerned with the family history and the personal medical history of the applicant, are to be filled in by the applicant before the medical examination is undertaken. In the second part there is a special section dealing with sexual problems, and the answers given to the questions therein should permit the sympathetic physician to remove a great many barriers to a successful and happy marriage. Part 3 provides a most excellent guide for the doctor in his physical examination of the applicant. It is to be noted that the schedule is to be issued only to doctors, and it is in no sense a certificate. Nowhere in it is the doctor asked to certify that the applicant is fit or unfit either for marriage or procreation.

In order to help practitioners who are not wellinformed in the field of human genetics, the Society has appointed a small board of specialists who may be consulted about problems of heredity. It is not stated to whom the doctor may turn for help in dealing with the marriage bureau kind of problem.

Without doubt the scheme is a most excellent one, not so much because, through its help, either the practitioner or the board of specialists will be able to offer compelling advice to any given individual or pair, but because it can, and probably will, encourage the development of a eugenic conscience (though probably only in the middle. class where such a conscience already exists), and furthermore because, if properly employed, it can be the means of adding greatly to our knowledge concerning the reasons for the success or otherwise of marriage in individual cases, and of the incidence and mode of inheritance of pathological characters in mankind. But two things must make the working of the scheme difficult. One is that exceedingly few medical men of the present generation know anything of sexual psychopathology or of the principles of genetics, and the other is that our knowledge of human genetics is exceedingly slight and most imperfect.

However, the project is a step in the right direction, right in the sense that it, a purely voluntary scheme devised by a private society, is undoubtedly an intelligent anticipation of what will be, in the not too distant future, a compulsory scheme backed by law. The State is bound, in its own interests, sooner or later to place its sentinels at the portals of birth, for it is by this route that most of our undesirables enter the realm. 